\title{
Empirical Validation of Building Energy Modeling using Flexible Research Platform
}

\author{
Piljae $\operatorname{Im}^{1}$, Joshua R New ${ }^{1}$, Jaewan Joe ${ }^{1}$ \\ ${ }^{1}$ Oak Ridge National Laboratory, Oak Ridge, United States of America
}

\begin{abstract}
Recently, efforts have been made to provide reliable empirical data for ANSI/ASHRAE Standard 140, Standard Method of Test for the Evaluation of Building Energy Analysis Computer Programs, to enable improved accuracy of building energy model (BEM) engines and improved characterization of their accuracy. The motivation for this effort is that the use of reliable empirical validation data sets in the evaluation of building energy modeling tools will lead to more consistent and validated simulation engines across all software vendors. This would expedite the use of building energy modeling in designing new buildings and retrofitting existing buildings, which delivers more energy-efficient buildings.
\end{abstract}

As part of a three-year multi-lab empirical validation project sponsored by U.S. DOE, this research project generated cooling season test plans by reviewing ASHRAE Standard 140, and the tests were performed based on the test plan. Finally, the experimental data sets were compared with the EnergyPlus model to demonstrate the validation procedure.

\section{Introduction}

Building Energy Modeling (BEM) has been used extensively in a new building and retrofit design, code compliance, green certification, qualification for tax credits and utility incentives, and real-time building control. However, insufficient characterization of BEM engine accuracy and resultant lack of confidence in BEM has been a barrier to expedite the use of BEM in industries and academia. Thus, there has been an immediate need for comprehensive validation of BEM tool accuracy.

Different approaches for validating the building energy model accuracy exist; comparative (inter-model comparison), analytic and empirical validation methods as defined in ASHRAE standard 140 (ANSI/ASHRAE, 2014; Judkoff \& Neymark, 2006). The comparative study is limited to simulation comparison without the ground truth. The analytic method also can hardly be free from the limitations inherent in the simulation as it is the comparison of the models even though the simplified model might be originally developed from the experiment. On the other hand, the empirical validation method compares the simulation results to the measured data from a real building or test cell, therefore, this validation methodology has the highest potential to validate building energy simulation tools for accurately predicting the actual energy performance. Due to the nature of this methodology, however, it would need significant engineering/instrument cost and exploits to monitor the data to reduce the uncertainties in building input parameters. This method would be prevailed due to the technology development for sensing and data acquisition systems and its deployment to actual buildings.

In this regard, international efforts for developing the empirical validation method have been made by IEA (International Energy Agency) for several decades with Annex 58, Reliable Building Energy Performance Characterisation Based on Full-Scale Dynamic Measurements (IEA 2017). Test-sets with confined environments and actual buildings were investigated by international participants and used for the validation of simulation models. However, those efforts are limited only to the investigation on the building envelope (fabric) by evaluating the overall heat loss. Combining the in situ experimental data from Heating, Ventilation, and Air Conditioning (HVAC) system in empirical validation is challenging due to the heterogeneous thermal behavior of the building physics and HVAC systems. Nevertheless, this thorough approach would advance the empirical validation for reliable energy performance assessment.

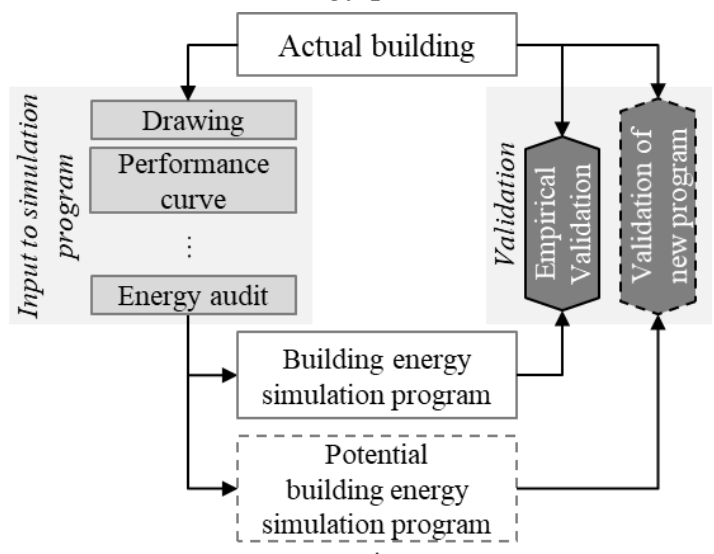

Figure 1: Conceptual diagram of the project

Also, nation-wide efforts are being made to expand the capability of the ASHRAE standard 140. Its objective is to provide the complete empirical validation data set for tool evaluation as seen in Figure 1, and development beyond the existing class I and II that utilize the simulation platform. This three-year multi-lab empirical 
validation project sponsored by U.S. DOE Building Technologies Office (BTO) has been performed from 2016 through 2018. Major outputs of this project include 1) empirical validation of a multizone HVAC (heating, ventilating, and air-conditioning) system using ORNL's Flexible Research Platform (FRP) (ORNL), 2) generation of a performance map for high-performance rooftop units (RTUs) (National Renewable Energy Laboratory [NREL]), 3) empirical validation of building envelope models using Lawrence Berkeley National Laboratory's FLEXLAB measurement (LBNL), and 4) uncertainty characterization for experimental measurement (Argonne National Laboratory (ANL)). The project has generated multiyear validation test plans, model input specifications, and more than 20 documented tests and operational configurations.

\section{Objectives}

The main objective of the project is to document data sets that can be used to validate key functionality in different energy simulation tools and to identify errors and inadequate assumptions in simulation engines so that developers can correct them. This paper focuses on empirical validation efforts utilizing ORNL's FRP, which is an occupancy emulated small office building. While the previous studies are generally limited to simple cases (Judkoff et al 2008, Strachan et al 2015), the empirical validation utilizing FRP would provide unique data sets for more realistic multizone buildings found in the real world. Figure 1 shows the conceptual diagram of the project.

\section{Test-bed}

\section{Building characteristics}

The two-story FRP, consisting of slabs and a steel superstructure with a footprint of $13.4 \mathrm{~m}$ by $13.4 \mathrm{~m}$ representative of light commercial buildings common in the nation's existing building stock (Figure 2 and Table 1). The FRP has 10 conditioned zones with 2 unconditioned zones (i.e., staircase) with $0.4 \mathrm{~m}$ thick exterior wall. The FRP is an unoccupied research apparatus in which occupancy is emulated by process control of lighting, humidifiers for human-based latent loading, and a heater for miscellaneous electrical loads (MELs). The occupancy emulation would drastically reduce the occupancy behavior related to uncertainty in modeling.

The test building is exposed to natural weather conditions for research and development leading to the system- and building-level advanced energy efficiency solutions for new and retrofit applications. To reduce the uncertainty from ground heat transfer through the slab, $0.3 \mathrm{~m}$ Geofoam EPS46 ( $\left.R_{\mathrm{us}}-55\left(\mathrm{R}_{\mathrm{SI}}-9.7\right)\right)$ insulation was installed in the floor. Windows are evenly distributed except east and north side of the $1^{\text {st }}$ floor with $28 \%$ of windows to wall ratio.

\section{HVAC systems}

The multi-zone HVAC system used for this validation tests incorporate a $44 \mathrm{~kW}$ (12.5 ton) RTU and a natural gas furnace. The RTU has a 9.6 energy efficiency rating
(EER) with two scroll compressors and one central fan with variable frequency drive (VFD). Each room is conditioned with variable-air-volume (VAV) box with electric resistance reheat. The original intake for the fresh air in the RTU was blocked to reduce the uncertainty of the test results.
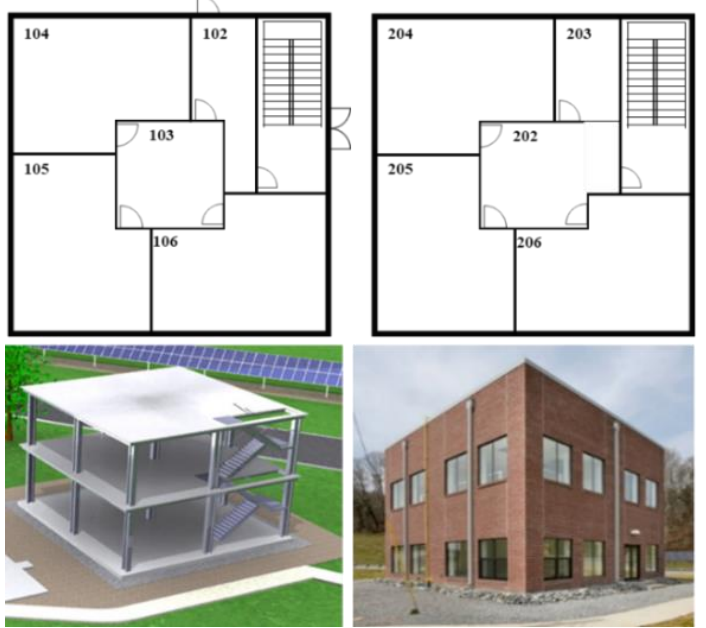

Figure 2. Plan drawing (top), front view(bottom right), and structural view (bottom left).

Table 1: Descriptions of FRP.

\begin{tabular}{|c|c|}
\hline Location & Oak Ridge, Tennessee, USA \\
\hline $\begin{array}{c}\text { Building } \\
\text { size }\end{array}$ & $\begin{array}{c}\text { Two-story, } 12.2 \mathrm{~m} \times 12.2 \mathrm{~m}(40 \times 40 \mathrm{ft}), 4.3 \mathrm{~m} \\
(14 \mathrm{ft}) \text { floor-to-floor height }\end{array}$ \\
\hline $\begin{array}{c}\text { Exterior } \\
\text { walls }\end{array}$ & $\begin{array}{c}\text { Concrete masonry units with face brick, RsI- } \\
1.9 \text { (RUs-11) fiberglass insulation }\end{array}$ \\
\hline Floor & Slab-on-grade \\
\hline Roof & $\begin{array}{c}\text { Metal deck with RsI }-3.17(\mathrm{Rus}-18) \\
\text { polyisocyanurate insulation }\end{array}$ \\
\hline Windows & $\begin{array}{c}\text { Double-pane clear glazing, } 28 \% \text { window-to- } \\
\text { wall ratio }\end{array}$ \\
\hline Baseloads & $\begin{array}{c}\text { lighting density : } 9.18 \mathrm{~W} / \mathrm{m}^{2}\left(0.85 \mathrm{~W} / \mathrm{ft}^{2}\right), \\
\text { equipment density: } 14.04 \mathrm{~W} / \mathrm{m}^{2}\left(1.3 \mathrm{~W} / \mathrm{ft}^{2}\right)\end{array}$ \\
\hline $\begin{array}{c}\text { HVAC } \\
\text { system }\end{array}$ & $\begin{array}{c}44 \mathrm{~kW}(12.5 \text { ton), } 9.7 \mathrm{EER} \text { rooftop unit; } 81 \% \\
\text { AFUE natural gas furnace; } \mathrm{VAV} \text { with electric } \\
\text { reheat }\end{array}$ \\
\hline
\end{tabular}

\section{Instrumentation and monitoring}

The Johnson Controls Metasys system, a dedicated energy management control system, is deployed in the FRP; and the room setpoint temperature, schedule, and other controls were predefined through the Metasys system. In addition, the data acquisition hardwareincluding 1 master cabinet, 4 peripheral cabinets, 256 thermistor channels, 256 single-ended voltage channels, 100 thermocouple channels, and 64 frequency input (or 5 V) control channels - is currently deployed in the FRP. The sensors used for monitoring are calibrated.

The measurements include the zone setpoint temperature and humidity, supply and return air temperature and flow rates, and energy consumption of individual components including a compressor, condenser, supply fan, VAV reheating. The data are available in $1 \mathrm{~min}, 15 \mathrm{~min}$, and 60 min intervals. A dedicated weather station on the roof of the FRP monitored the weather data including outdoor air temperature, humidity, solar radiation (i.e., direct normal, diffuse, and global), and wind speed and direction. 


\section{Methodology}

In this study, no exploits of the calibration are made for the simulation model. But significant factors affecting the model behavior are dealt with in situ experimental data; e.g., performance curves are generated from the measurement of actual test-bed and input to the simulation model (i.e., EnergyPlus, 2019) accordingly as it is. This section discusses those key parts of the simulation inputs and explains the experiment settings. Followings are the main factors that are input based on the experimental data accordingly.

- Infiltration

- RTU performance curve

- Fan performance curve

- Duct leakage

\section{Key inputs for the simulation model}

Building envelope and HVAC systems are built and generated from OpenStudio (OpenStudio SketchUp Plugin, 2019) and then simulated in EnergyPlus 8.0 (EnergyPlus, 2019) environment. All simulation settings are based on the building design, drawings, and HVAC systems. The inside surface convection algorithm is set to "CeilingDiffuser" to be consistent with the building system layout, while outside remains default.

In order to take account of the leakage, the whole building infiltration rate was measured using a blower door test. Based on the infiltration modeling guideline for commercial building energy analysis (Gowri, Winiarski, \& Jarnagin, 2009), 3.15E-04 $\mathrm{m}^{3} / \mathrm{s} \cdot \mathrm{m}^{2}$ (flow per exterior surface area) is input to "ZoneInfiltration: DesignFlowRate". Coefficients for temperature difference and wind velocity remains default.

$$
I_{\text {design }}=\left(\alpha_{\text {bldg }}+1\right) \cdot I_{75 p a}\left(0.5 \mathrm{C}_{\mathrm{s}} \rho \mathrm{U}_{\mathrm{H}^{2}} / 75\right)^{\mathrm{n}}
$$

Where:

$\mathrm{U}_{\mathrm{H}}$ : the wind speed at building height $(4.47 \mathrm{~m} / \mathrm{s})$

$\rho:$ the density of air $\left(1.18 \mathrm{~kg} / \mathrm{m}^{3}\right)$

$\mathrm{C}_{\mathrm{s}}$ : the average surface pressure coefficients $(0.1617)$

$\alpha_{b l d g}$ : an urban terrain environment coefficients $(0.22)$

$I_{75 p a}$ : the building leakage rate at $75 \mathrm{~Pa}$

$n$ : coefficient (0.65)

Another significant factor affecting the building energy performance is the HVAC system, which is a packaged DX cooling system in this study. In EnergyPlus, the DX cooling electricity consumption $\left(P_{\text {elec }}\right)$ is calculated based on three performance curve fits (Equation 2). Those are polynomial curves ( $f$ in Equation 1) that are used to characterize the performance of HVAC equipment, which are equipment capacity, EIR (Energy Input Ratio), and run-time fraction (RTF) taking account the cycling impact. The feature data of those polynomials are temperatures (entering cooling coil and condenser), airflow rate, and part load ratio (PLR).

$$
P_{\text {elec }}=\boldsymbol{C a p} \cdot \boldsymbol{E I R} \cdot \boldsymbol{R T F}
$$

where:

$\boldsymbol{C a p}=Q_{\text {rated }} \cdot f_{\text {Cap }, \text { Temp }} \cdot f_{\text {Cap flow }}$
$\boldsymbol{E I R}=\left(1 /\right.$ COP $\left.P_{\text {rated }}\right) \cdot f_{\text {EIR,Temp }} \cdot f_{\text {EIR,flow }}$
$\boldsymbol{R T F}=P L R / f_{P L R}(P L R)$

In order to create the performance curve, quasi-steadystate data are filtered from 1 year of HVAC operation data in 1 min resolution neglecting the transition period; 6 and 4 min data was excluded for the starting/ending times and transition times between the stages. Coefficients of the polynomials are regressed with measured power consumption and feature data using the HVAC Performance Curve Fit Tool (EnergyPlus, 2019). Figure 3 shows the RTU power consumption of measurement and simulation. As this system is a two-stage unit, the plot shows the low and high stage energy use distinctly.

RTU power consumption

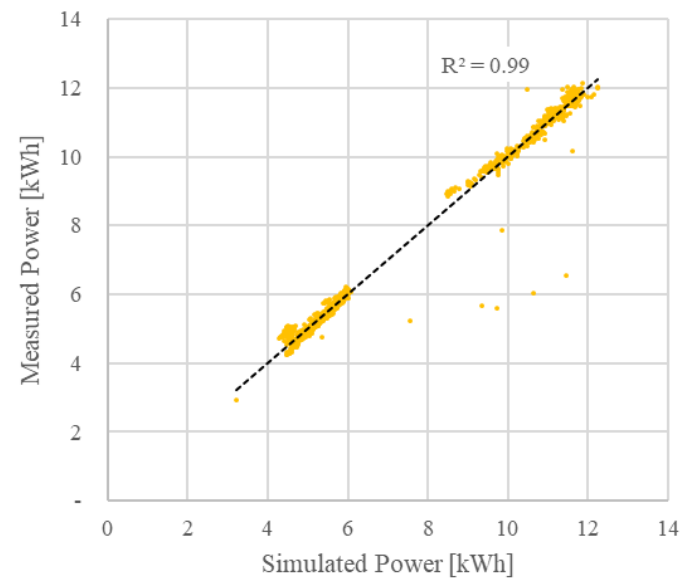

Figure 3: RTU model validation

Figure 4 shows the RTU performance comparison with a generic curve from EnergyPlus open dataset (Lennox KCA120S4) and the fitted model. The obvious discrepancy of the performances between the two curves is observed.

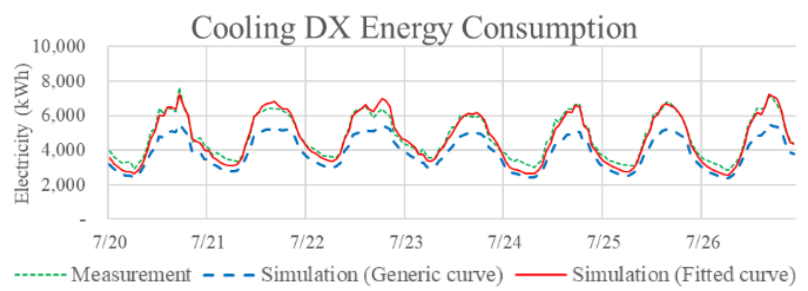

Figure 4: RTU performance comparison

Fan model is also included as shown in Figure 5. The second order polynomial of airflow fraction (actual flow/design flow) is generated with experimental data and input to the simulation.

Lastly, the effect of the duct leakage was input to the model. Ideally, it depends on the construction and length of each duct which can be hardly estimated. In order to estimate the rough amount of the leakage, the airflow rate in RTU was compared with total airflow rates in VAV sides. $23 \%$ of the airflow is assumed to be leaked from the duct between the RTU and each VAV boxes. It is set in Nominal Upstream Leakage Fraction at ZoneHVAC:AirDistributionUnit. 


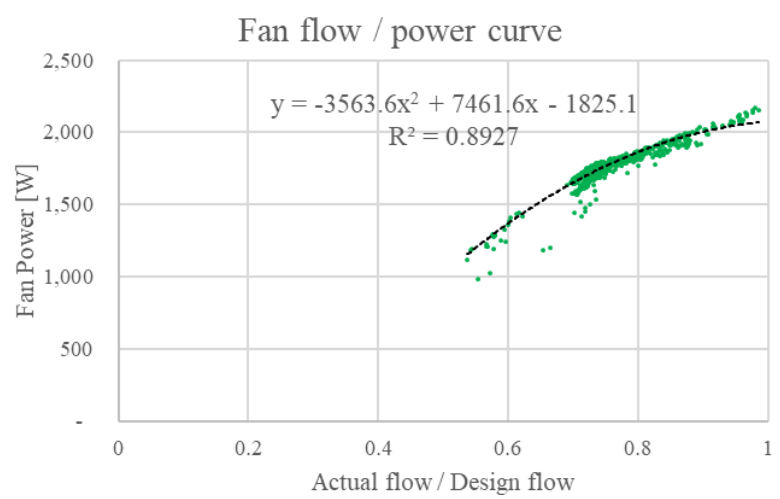

Figure 5: Fan model validation

\section{Experimental design}

The following measuring points are used in this validation study. Data will be provided in $15 \mathrm{~min}$, and $60 \mathrm{~min}$ resolution.

- Delivered cooling energy consumption $(\mathrm{kWh})$

- Cooling DX electricity consumption (kWh)

- Supply fan electricity consumption (kWh)

- Zone temperature $\left({ }^{\circ} \mathrm{C}\right)$

ASHRAE 140 provides mechanical cooling/heating base cases CE100 and CH100. However, the building/system specifications for these cases are not consistent with the current FRP setup. The FRP is a two-story building with ten thermal zones exposed to real weather conditions. These cases are not intended to be used with a real building, but only with building energy models. The test conditions for cases CE100 and CH100, including the building envelope requirements, are not suitable for any real building. For example, the wall/roof/floor insulation $\mathrm{R}$-values defined in these cases are less than $100 \mathrm{~m}^{2} \cdot \mathrm{K} / \mathrm{W}$ $\left(567 \mathrm{~h} \cdot \mathrm{ft}^{2} \cdot{ }^{\circ} \mathrm{F} / \mathrm{Btu}\right)$, and the infiltration rate is zero, which cannot be realized in real buildings. Therefore, the test plan for the multi-zone HVAC validation refers only to a selected set of ASHRAE 140's HVAC test conditions that can be realized in the current FRP setup. Given the objective of this study to provide a set of empirical data from a high-fidelity test facility, this would fulfill the objectives.

ASHRAE 140 case CE100, CE 110, CE 120, CE130, CE 150, CE160, and CE165 were reviewed, and they were applied as described or modified as applicable to the FRP. An RTU with a VAV will be used as a cooling season test. The cooling season tests were performed during summer 2018.

\section{Test 1: Baseline Case}

As a baseline case test, a building as-is was tested. There were no other treatments, such as blocking windows, adding additional envelope insulation, and so on. The testing includes the following other test conditions.

- Window blinds are not used.

- No sensible or latent internal loads are emulated.

- A fixed discharge temperature of $12.7^{\circ} \mathrm{C}\left(55^{\circ} \mathrm{F}\right)$ for RTU and no OA or exhaust air provision (same as CE100) are set.

- Fixed static pressure (i.e., $249 \mathrm{~Pa}(1$ " w.c.)) is maintained.
- Room thermostat cooling setpoint temperature is maintained at $22.2{ }^{\circ} \mathrm{C} \quad\left(72^{\circ} \mathrm{F}\right)$ with a possible minimum dead band. There is no setback/set-up schedule, no humidity control. Heating is turned off including main gas furnace and VAV reheating.

Test 2: Increased thermostat set point

The original test plan was that the thermostat set-point is increased to $26.7{ }^{\circ} \mathrm{C}$ (80F), and other conditions are kept the same as in the cooling baseline case (i.e., Test 1). However, based on the observation from Test 1, the condition for the cooling season Test 2 was redefined. All the original test plan has remained the same, but the RTU discharge air temperature increased to $15.6{ }^{\circ} \mathrm{C}$. The main purpose of Test 2 is to reduce the cooling loads by reducing the thermostat setpoint. But, as noticed in Test 1 , the rooms are overcooled in general mainly due to the independent controls of the RTU AHU and VAV boxes, and reducing thermostat setpoint cannot reduce the cooling load. As the RTU discharge temperature was increased to $15.6{ }^{\circ} \mathrm{C}$, however, the cooling load was reduced as intended for the Test 2 .

\section{Results}

\section{Evaluation metrics and validation output}

In this study, Normalized Mean Bias Error (NMBE) and Coefficient of Variation of the Root Mean Square Error $(\mathrm{CV}(\mathrm{RMSE}))$ were used for quantifying the deviation between the measurement and simulation. $M, S$, and $n$ represent the measurement, simulation, and the number of data, respectively. Upper bar refers to the average. Both show the discrepancy in percentage so the lower value indicates the more accurate simulation results. And over or underfitting can be detected from the NMBE with a sign.

$$
\begin{gathered}
\mathrm{NMBE}=\frac{1}{\bar{M}} \cdot \frac{\sum_{i=1}^{n}\left(M_{i}-S_{i}\right)}{n} \times 100 \\
\mathrm{CV}(\mathrm{RMSE})=\frac{1}{\bar{M}} \sqrt{\frac{\sum_{i=1}^{n}\left(M_{i}-S_{i}\right)^{2}}{n}} \times 100
\end{gathered}
$$

\section{Test 1: Baseline Case - 7/20/2017 through 7/26/2017}

During the Test 1 , the VAV reheating was turned off. As the VAV reheating was turned off, it was observed that the room temperature never reaches $72 \mathrm{~F}$ except for the room temperature for west-facing rooms during the late afternoon. The main reason for the low room temperature is the minimum damper positions for $10 \mathrm{VAV}$ boxes. Although the cooling load of a room has been met (i.e., no needs for cooling), minimum airflow to the room is maintained, which over cools the rooms. In typical VAV reheating operation, the discharge air should be reheated not to over cool the rooms. However, during this test, all the reheating was turned off, which might cause overcooling the rooms.

In general, the building energy model uses a constant RTU supply air temperature setpoint as the input parameter, which would show some discrepancies with 
the measured supply air temperature. In the simulation, instead of using constant supply air temperature setpoint, the measured hourly supply air temperature was input to the model to reduce the discrepancy.

\section{Weather Condition}

Figure 6 shows the hourly outdoor air temperature, relative humidity, and solar radiation during the test period. The data shows that the hourly pattern of the outdoor temperature and $\mathrm{RH}$ have been relatively consistent throughout the test period except $7 / 23$. The same consistency was found for the hourly global solar radiation. During the test period, the maximum and minimum outdoor air temperature is about $34.3{ }^{\circ} \mathrm{C}(93.8 \mathrm{~F})$ and $20^{\circ} \mathrm{C}(68.0 \mathrm{~F})$, respectively.

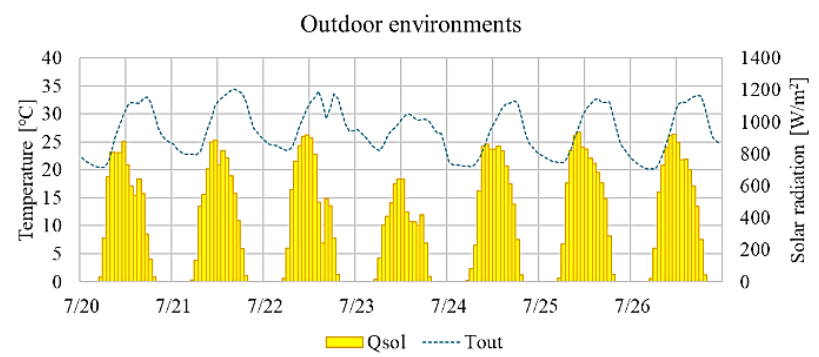

Figure 6: Hourly Outdoor air temperature and solar radiation for Test 1

\section{HVAC Operations}

Figure 7 shows the measured and simulated hourly profiles of RTU energy consumption. The upper one shows cooling energy (i.e., enthalpy difference) and the lower one shows the electricity consumption from the cooling coil system (compressor and condenser fan). Both simulation profiles are matched well with experimental data. The calculated hourly NMBE and CV(RMSE) are $2.6 \%$ and $5.9 \%$ in delivered cooling and $2.4 \%$, and $5.8 \%$ in cooling DX electricity, respectively.

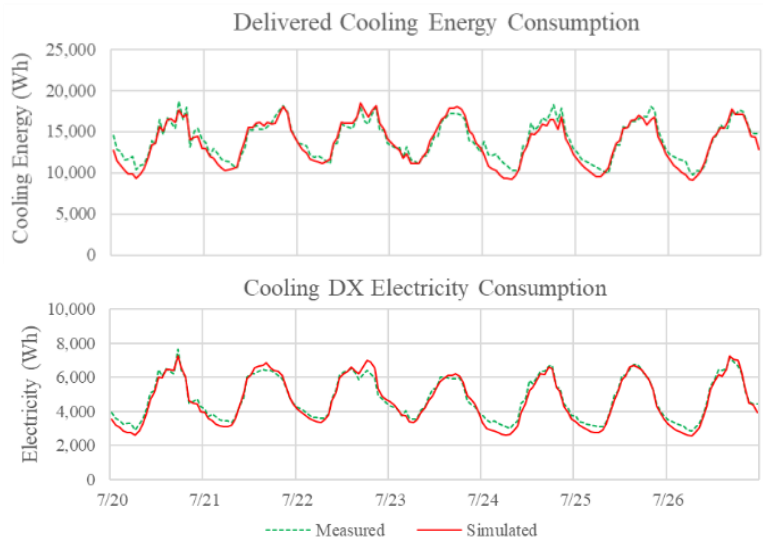

Figure 7: Hourly cooling energy comparison for test 1 (upper: delivered cooling energy, lower: DX electricity consumption)

Figure 8 shows the fan energy consumption profiles of simulation and experiment; a good agreement is observed. The hourly NMBE and CV(RMSE) are $0.3 \%$ and $0.7 \%$, respectively.

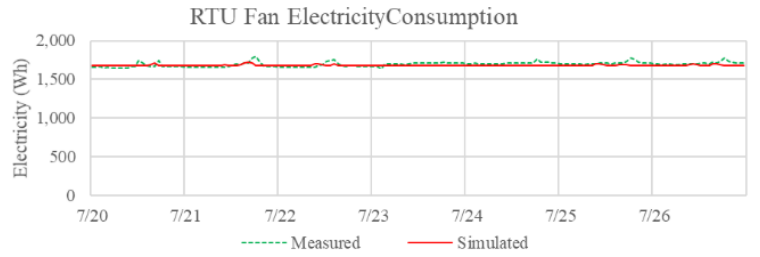

Figure 8: RTU fan energy comparison for test 1

The simulated and measured total building HVAC consumption is compared in Figure 9. It shows that the measured total HVAC energy consumption is about $2.0 \%$ higher than the simulated consumption.

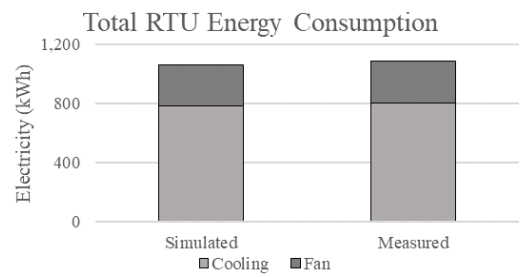

Figure 9: Total HVAC energy comparison for test 1

\section{Zone Temperature}

In comparisons of room air temperatures, most simulated data show good matches with measurement. Figure 10 shows the best (Room 104) and worst (Room 206) cases for typical perimeter zones; RMSE of each case are 0.62 ${ }^{\circ} \mathrm{C}$ and $2.04{ }^{\circ} \mathrm{C}$, and weight-average (with room dimension) RMSE is $0.86{ }^{\circ} \mathrm{C}$. Room 104 is Northwest perimeter zone and shows the best result as it is relatively less exposed to the solar radiation. On the other hands, South face zones show less accuracy. Further investigation is being undergone to identify the possible cause for the discrepancy. One potential cause of the discrepancy is a varied level of zonal infiltration. The single infiltration rate estimated from a whole building blower door test was applied to individual zone consistently. As each zone may have varied level of infiltration rate due to exterior doors for some zones and other zone-specific configurations, further investigation for varied zonal infiltration rate is planned using multizone tracer gas test.

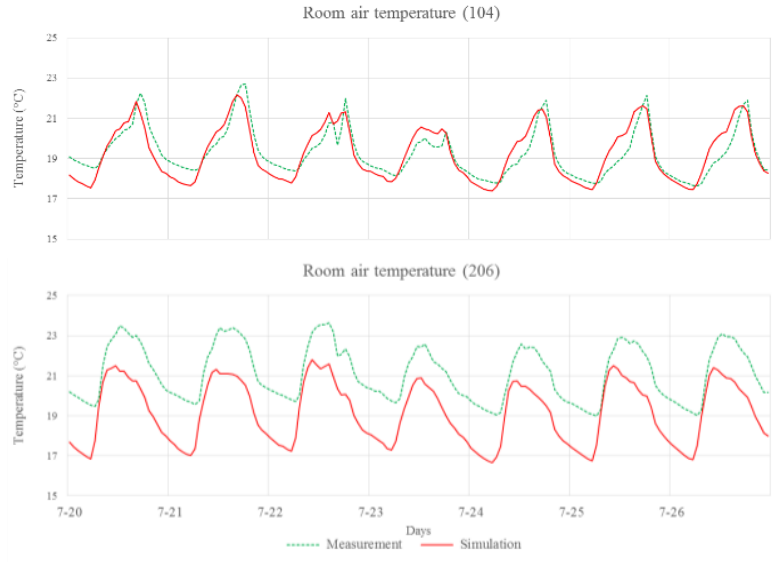

Figure 10: Room air temperature comparison for test 1 (upper: best case, lower: worse case) 


\section{Test 2: Increased thermostat set point $-7 / 29 / 2017$}

\section{through 8/3/2017}

As previously discussed, setting a higher set-point temperature was not able to realize the reduced cooling load due to the minimum damper position of the VAV. Instead, the supply air temperature was increased to 15.6 ${ }^{\circ} \mathrm{C}$ from $12.7^{\circ} \mathrm{C}$.

\section{Weather Condition}

Figure 11 shows the hourly outdoor air temperature, relative humidity, and solar radiation during the test period. Based on the solar radiation plot, it appears there are two clear days (7/30 and 7/31), while other days were partly sunny and/or cloudy.

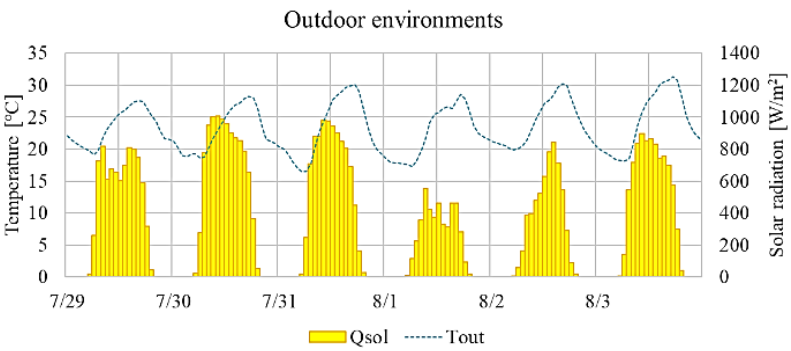

Figure 11: Hourly outdoor air temperature and solar radiation for Test 2

\section{HVAC Operations}

Figure 12 shows the measured and simulated hourly profiles of RTU energy consumption. The upper one shows cooling energy (i.e., enthalpy difference) and the lower one shows the electricity consumption from the cooling coil system (compressor and condenser fan). Both simulation profiles are matched well with experimental data in a similar fashion with Test 1 . The calculated hourly NMBE and CV(RMSE) are $7.9 \%$ and $10.9 \%$ in delivered cooling and $2.5 \%$, and $5.3 \%$ in cooling DX electricity, respectively.

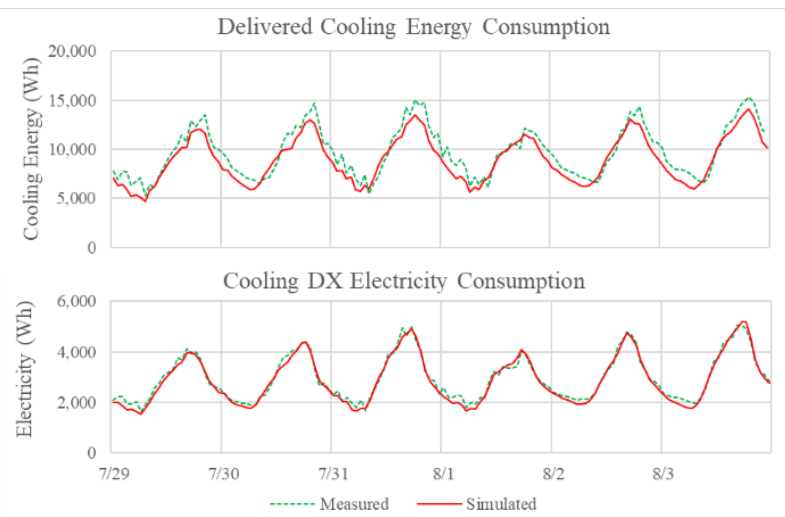

Figure 12: Hourly cooling energy comparison for test 2 (upper: DX electricity consumption, lower: delivered cooling energy)

Figure 13 shows the fan energy consumption profiles of simulation and experiment; a good agreement is observed. The hourly NMBE and CV(RMSE) are $0.8 \%$ and $1.45 \%$, respectively.

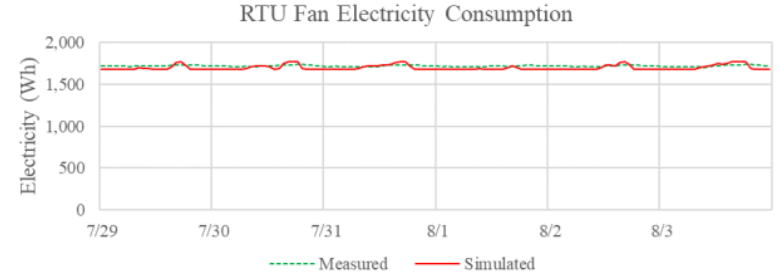

Figure 13: RTU fan energy comparison for test 2

The measured and simulated total HVAC energy use during the test period was compared in Figure 14. Total measured HVAC energy use (i.e., cooling, and fan) is about $2.1 \%$ higher than the simulated HVAC energy use.

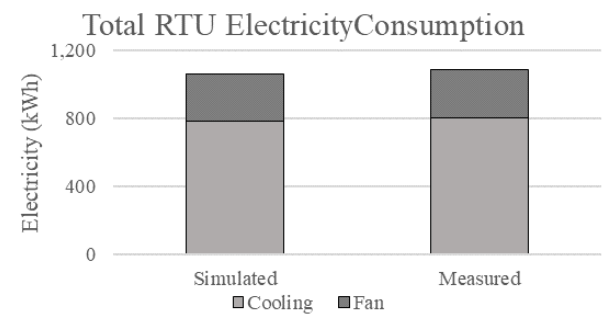

Figure 14: Total HVAC energy comparison for test 2

Zone Temperature and $R H$

In a similar fashion with Test 1, most simulated temperature profiles show good matches with measurement. Figure 15 shows the best (Room 203) and worst (Room 206) cases; RMSE of each case are $0.39^{\circ} \mathrm{C}$ and $1.67^{\circ} \mathrm{C}$, and weight-average (with room dimension) RMSE is $0.79^{\circ} \mathrm{C}$. A similar trend is shown in Test 2; South face zones show less accuracy compared to others.

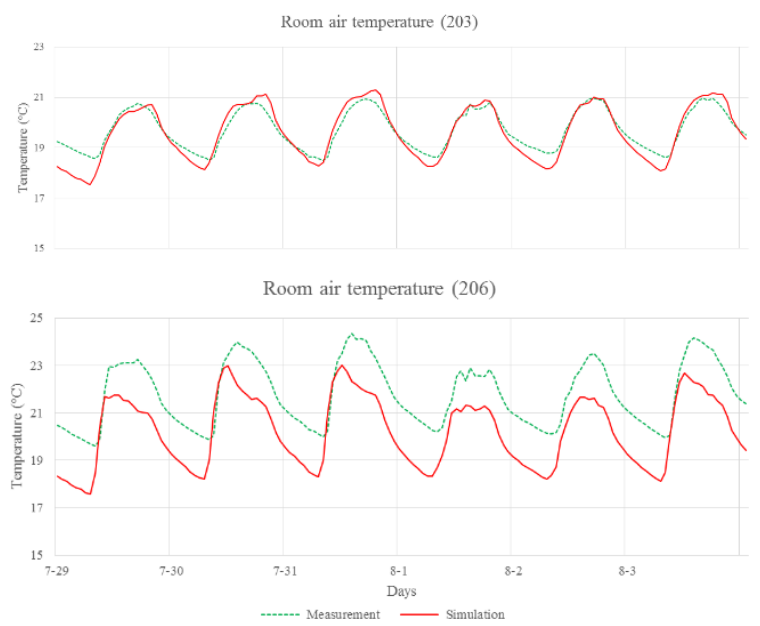

Figure 15: Room air temperature comparison for test 2 (upper: best case, lower: worse case)

\section{Conclusions}

Two sets of cooling season tests were performed, and the results were compared with the simulations. EnergyPlus model is built from the as-built drawings and in situ experimental data without the calibration efforts.

Followings are the major findings:

- Simulation and experimental energy consumption of the RTU are matched well. Hourly NMBE and 
CV(RMSE) are less than $2.5 \%$ and $5.8 \%$ for both Tests.

- Matching the room air temperature profiles is limited without further detailed modeling and calibration.

\section{Discussions and limitations}

During the test, several challenges in measurement and simulation were identified as followings.

- Infiltration: target building is a multizone building, which has 10 different rooms facing different orientations. Although each room has a similar configuration and building material/constructions, there should be a different level of zone infiltrations as some zones have exterior doors, more holes due to extra pipe works, etc. Therefore, individual zone infiltration level would be identified for a better understanding of this issue. Tracer gas test is planned for the ongoing project.

- Duct leakage: while the total RTU airflow has been monitored, there are no individual VAV airflow stations. In order to verify the possible duct leakage, VAV box airflow should be measured. In addition, once duct leakage is suspected from the measured data, the exact location of the duct leakage, and duct leakage to the outside or plenum area should also be estimated separately for precise modeling.

- Zone mixing: current EnergyPlus model does not adequately address the inter-zone mixing unless one uses detailed Airflow Network model. The inter-zone air mixing, which occurs in a real building and will impact the temperatures in the adjacent rooms.

- Part load ratio: current RTU model is regressed with only EIR and Capacity and default curve is used for the part load ratio which is linear. Further investigation is needed for better modeling quality.

- Uncertainty quantification: As part of the multi-lab efforts, ANL is performing an uncertainty quantification of the measured data and simulation input uncertainties. Given the nature of empirical validation, this will provide better metrics to compare the measured data with the simulation results. This effort was not described in the paper but will be published in the near future.

This work is a part of the three-year multi-lab project with LBNL, NREL, and ANL. Only basic building data along with HVAC data is distributed and input to the model and comparative study is carried out in parallel in order to validate the methodology of the project. Interested readers can find related works.

\section{Acknowledgment}

This material is based upon work supported by the U.S. Department of Energy, Office of Science, and Building Technologies Office. This research used resources of the Oak Ridge National Laboratory Building Technologies Research and Integration (BTRIC), which is a DOE
Office of Science User Facility. This work was funded by fieldwork proposal CEBT105 under DOE Building Technology Office Activity Numbers BT0302000 and BT0305000. This manuscript has been authored by UTBattelle, LLC, under Contract Number DEAC0500OR22725 with DOE. The United States Government retains and the publisher, by accepting the article for publication, acknowledges that the United States Government retains a non-exclusive, paid-up, irrevocable, worldwide license to publish or reproduce the published form of this manuscript, or allow others to do so, for United States Government purposes.

\section{References}

ANSI/ASHRAE Standard 140-2014. Standard Method of Test for the Evaluation of Building Energy Analysis Computer Programs. (2014). Atlanta, GA: American Society of Heating, Refrigerating, and AirConditioning Engineers.

EnergyPlus. (2019). US Department of Energy. https://energyplus.net/ (accessed Jan 2019).

Gowri, K., Winiarski, D., \& Jarnagin, R. (2009). Infiltration Modeling Guidelines for Commercial Building Energy Analysis. U.S. Department of Energy, (September), 21. https://doi.org/PNNL18898.

IEA (International Energy Agency). (2017). Reliable Building Energy Performance Characterisation Based on Full Scale Dynamic Measurements (Annex 58), project summary report.

Judkoff, R., \& Neymark, J. (2006). Model validation and testing: The methodological foundation of ASHRAE Standard 140. ASHRAE Transactions, 112 PART 2, 367-376.

Judkoff, R., Wortman, D., O'Doherty, B., and Burch, J. (2008). A Methodology for Validating Building Energy Analysis Simulation. Kansas City: National Renewable Energy Laboratory.

OpenStudio sketch-up extension. (2019). https://extensions.sketchup.com/sv/content/openstudi o-100 (accessed Jan 2019).

Strachan, P., Svehla, K., Heusler, I., \& Kersken, M. (2015). Whole model empirical validation on a fullscale building. Journal of Building Performance Simulation, 9(4), 331-350. http://doi.org/10.1080/19401493.2015.1064480. 